\title{
Elderly Male Patient with Fibrotic Non Spesific Instertitial Pneumonia from Lung Biopsy by Video Assisted Thoracoscopy
}

\author{
Santony Santony ${ }^{1}$, Susanthy Djajalaksana ${ }^{1}$, Iin Noor Chozin ${ }^{1}$, Dini Rachma Erawati ${ }^{2}$, Hendy \\ Setyo Yudhanto ${ }^{3}$ \\ ${ }^{1}$ Pulmonology and Respiratory Department, Saiful Anwar Hospital, Universitas Brawijaya, Jaksa Agung Suprapto 2, Malang, 65112, Indonesia \\ ${ }^{2}$ Radiology Department, Saiful Anwar Hospital, Universitas Brawijaya, Jaksa Agung Suprapto 2, Malang, 65112, Indonesia \\ ${ }^{3}$ Pathology Anatomy Department, Saiful Anwar Hospital, Universitas Brawijaya, Jaksa Agung Suprapto 2, Malang, 65112, Indonesia
}

Abstract

Background: NSIP is a rare disease, the incidence rate ranges from 1 to 9 per 100,000 population, where most cases of NSIP are idiopathic. NSIP definitive diagnosis is very difficult because it must be with a multidisciplinary approach and confirm from a pulmonary biopsy. On the course of his illnesses the possibility of Connective tissue diseases (CTDs) arising in NSIP during follow up period was about $10 \%$ of cases.

Case Report: We reported one case at RS Dr. Saiful Anwar, an old adult male smoker, age 64 with fibrotic type Non Spesific Instertitial Pneumonia (NSIP). From clinical patients including anamnesis, physical examination and laboratory results and X-Ray chest, ILD suspicion was found. Bodypletstimography results show a corresponding decrease in DLCO with ILD. CTScan results obtained by crazy paving with pulmonary bronchiectasis traction in accordance with ILD susp Sussection NSIP and enforced from VATS biopsy results with conclusions according to NSIP description. Patients received corticosteroid therapy for 4 weeks and showed clinical improvement.

Conclusion: In these patients the diagnosis of fibrotic NSIP has gone through a multidisciplinary approach including the pulmonology, radiologist and pathologist sections. Corticosteroid therapy in these patients gives good results and the patient is in stable condition. Periodic monitoring is necessary because of the risk of exacerbations and the incidence of CTD complications..

Keywords: Fibrotic type, NSIP, VATS

MRJ 2020; 2(2):87-94

\section{Introduction}

Interstitial Lung Disease (ILD), which also

known as Diffuse Parenchymal Lung Disease

(DPLD), is a disease that pose as challenges

for physician. There are many difficulties in

establishing a diagnosis or classifying this

disease. The first reason being this particular

disease rarely occurs, and clinical feel the

lack of experience in establishing the diagnosis. Another reason

being the need of several experts in radiologic and pathologic department to establish a diagnosis. The third reason being poor prognosis and therapeutic reason of this dieae. $^{1}$

Non specific interstitial pneumonia

(NSIP) is a form of interstitial lung disease.

*Corresponding author:

Santony Santony (santonyliao@ymail.com)

Pulmonology and Respiratory Department, Saiful Anwar Hospital - Universitas Brawijaya, Jaksa Agung Suprapto St. No. 2, Malang. 65112, Indonesia 


\section{Case}

A 54-years-old male, admitted with dry cough, sometimes producing white phlegm since the last 2 years. Patient also complained shortness of breath since the last 2 years. Both complaints arose mostly after doing activities or having strenuous walks, but these complaints are not as severe as 2 years before. Patient has history of smoking 1-2 packs a day for around 30 years, and had stopped since 2015 due to shortness of breath. Patient had once been admitted to hospital in 2015 , diagnosed with pneumonia CAP,
Lung TB and Suspect

$\mathrm{Ca}$

bronchogenic sinistra TxNxM1a St IV.

From physical examination, no abnormality was found. Laboratory examination indicated increase in eosinophil,

lymphocyte, and monocyte differential count $(5,6 \%, 38,6 \%$, and $10 \%$ respectively) and decrease in neutrophil differential count $(44,9 \%)$, and slight decrease of natrium (113 $\mathrm{mmol} / \mathrm{L})$. NSE examination resulted 18,68. Anti ds-DNA, ANA test, and ANCA examination resulted in negative, as has BTA and Mollecular rapid test indicated no Mtb detected.

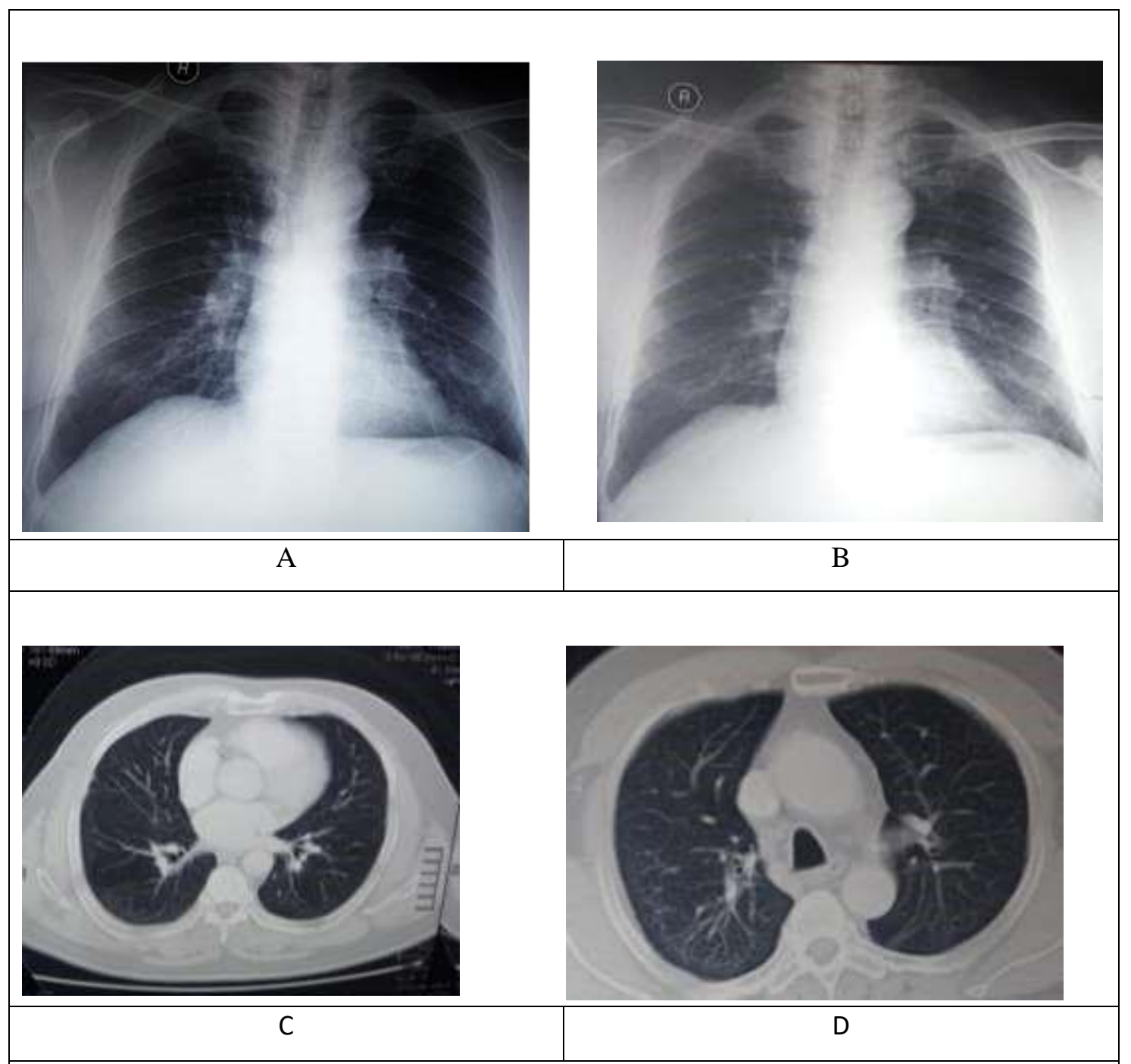

Chest XRay taken on April 25, 2017 and July 17, 2017 showed fibrotic pattern suspected Interstitial Lung Disease and confirming by Thorax CT Scan on June 13, 2017 showed crazy paving with lung bronkiektasis traction aligning to ILD radiological finding, susp NSIP dd chronic fibrotic hipersentivity 


\begin{tabular}{|c|c|c|c|c|c|c|c|c|c|}
\hline \multirow{3}{*}{$\begin{array}{c}\text { Body } \\
\text { Plethysmograph } \\
\text { Parame }\end{array}$} & \multirow{2}{*}{\multicolumn{3}{|c|}{$\begin{array}{l}\text { Before corticosteroid therapy } \\
\text { Without Bronchodilator }\end{array}$}} & \multicolumn{6}{|c|}{ After Corticosteroid therapy } \\
\hline & & & & \multicolumn{3}{|c|}{ Pre Bronohodilator } & \multicolumn{3}{|c|}{ Post Bronchodilator } \\
\hline & Prediction & Actual & Act/Ored & Prediction & Actual & Act/Ored & Prediction & Actua & Act/Ored \\
\hline IVC (L) & 3.25 & 1.91 & $59 \%$ & 3.25 & 2.39 & $61 \%$ & 3.9 & 2.42 & $62 \%$ \\
\hline VT (L) & & 0.63 & & & 0.85 & & & 0.56 & \\
\hline RAWtot (kPas/L) & $<0.30$ & 0.27 & $91 \%$ & $<0.30$ & 0.47 & $156 \%$ & $<0.30$ & 0.65 & $218 \%$ \\
\hline sRAWtot (kPas) & $<1.18$ & 0.82 & $69 \%$ & $<1.18$ & 0.94 & $80 \%$ & $<1.18$ & 0.74 & $62 \%$ \\
\hline TLC-He & 6.11 & 5.05 & $83 \%$ & 6.11 & 4.41 & $72 \%$ & 6.11 & 4.59 & $75 \%$ \\
\hline $\mathrm{RV}-\mathrm{He}(\mathrm{L})$ & 2.32 & 2.85 & $123 \%$ & 2.12 & 1.88 & $89 \%$ & 2.12 & 1.98 & $94 \%$ \\
\hline RV/TLC-He (\%) & 38 & 56 & $148 \%$ & 35 & 43 & $123 \%$ & 2.39 & $61 \%$ & $125 \%$ \\
\hline
\end{tabular}

Body Plethysmograph The spirometri before corticosteroid therapy showed slight diffusion disruption The spirogram on Pre and Post Bronkodilator after corticosteroid therapy showed slight diffusion disruption There is no increase of lung function after given bronchodilator

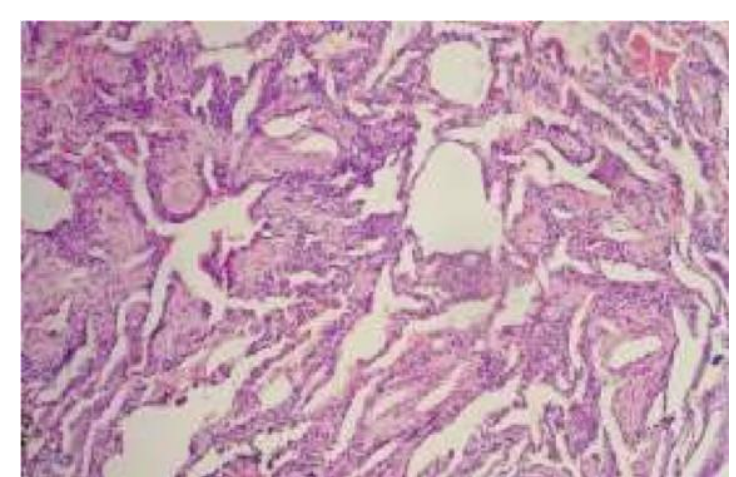

A

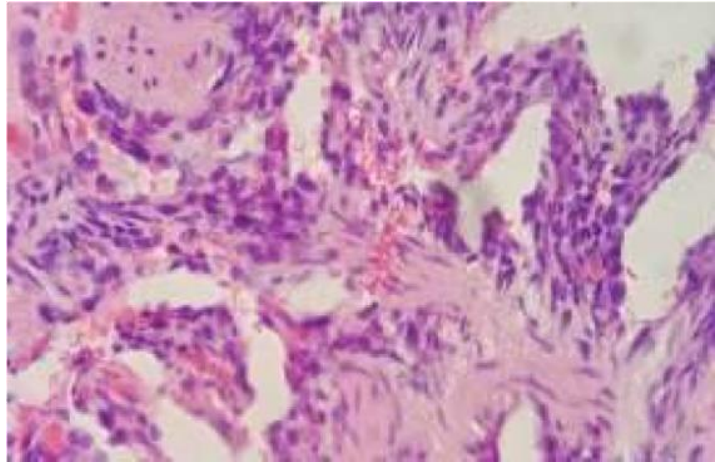

B

Histopathological of right superior lung lobe tissue taken from Lung Biopsy by VATS (September 8, 2017) with magnification 100 times (A) and 400x (B). Fibrosis showing on interstitial accompanied by lymphocyte inflammatory cells, histiocytes, plasma cells, erythrocyte extravasation, and distributed dust macrophage. Groups of aggregate lymphoid cells forming germinal centre appearance are also visible. Areas with thinning destructive alveolar septa appeared fit with Non Spesifik Instertitial Pneunomia

Based of findings above, patient was diagnosed with Idiopathic Non Specific Interstitial Pneumonia (NSIP) fibrotic type, and thus given corticosteroid: prednisone 4x5 mg, tappered off weekly for 4 weeks, i.e.
$4 \times 5 \mathrm{mg}$ on first week, $3 \times 5 \mathrm{mg}$ on second week, $2 \times 5 \mathrm{mg}$ on third week, and $1 \times 5 \mathrm{mg}$ on $4^{\text {th }}$ week. Patient was also given symptomatical therapy i.e. Concocted drugs (salbutamol $2 \mathrm{mg}$, CTM $2 \mathrm{mg}$, codein 10 
$\mathrm{mg}$, administered $3 \mathrm{x}$ a day, and retaphyl SR $2 \times 150 \mathrm{mg}$, as well as berotec inhaler 1 puff if patient felt difficulty in breathing.

\section{Discussion}

A 54-years-old male, admitted with dry cough, sometimes producing white phlegm since the last 2 years. Patient also complained shortness of breath since the last 2 years. Both complaints arose mostly after doing activities or having strenuous walks, but these complaints are not as severe as 2 years before. These data matches the incidence of NSIP, which increase in patient around the age or 40-60 years old. Predisposition of the case is more common in female, mostly nonsmoker, however it does not differ greatly from males. However in this case, the disease was found in a male smoker. According to studies, NSIP rarely occurs, however the actual case number is not clearly known. The case occurs in about $14 \% \quad-36 \%$ of idiopathic interstitial pneumonia cases, and could range from 1 to 9 in 100.000 population..$^{2,4,7}$

Based on literatures, NSIP commonly manifests as shortness of breath for a few months, often accompanied by coughs. Other symptoms could be fever and weight loss. This matches the patient's complaints, in which he felt shortness of breath and coughs for 2 years. But these symptoms are not specific and could be found in other lung diseases. ${ }^{2,3,4}$

Physical examination on the patient didn't lead to CTD, in which CTD is a spectrum of systemic autoimmune disorder, including rheumatoid arthritis, systemic lupus erythematous, idiopathic inflammatory myopathy, Sjogren syndrome, systemic sclerosis, and mixed connective tissue disease. The patient's problem, however, was leaning more towards idiopathic NSIP, even if it was said that in years to months to follow, CTD could be found in idiopathic NSIP. ${ }^{2,3}$

Radiological examination done in patient are chest XRay and Thorax CT Scan with contrast. Chest XRay showed infiltrate in middle and lower lung area, forming reticular pattern, and CT Scan showed ground glass opacity appearance accompanied by interlobular septal thickening on segmen 1,2, 3, with crazy paving appearance and bronchiectasis. This findings are in accordance to literatures in which was said that the most common CT scan finding in NSIP is bilateral groundglass opacities, and in fibrotic type NSIP, the most common finding is smooth reticular infiltrate. 
Consolidated area could be found, and in NSIP usually bilateral lungs are involved, predilected in lower lobe area, and traction bronchiectasis/bronchiolectasis are usually identified. $^{2,4}$

Patient thus underwent VATS lung biopsy to establish the diagnosis, and from anatomic pathology taken from VATS biopsy sample, findings were found : Fibrosis showing on interstitial, accompanied by lymphocyte inflammatory cells, histiocytes, plasma cells, erythrocyte extravasation, and distributed dust macrophage. Groups of aggregate lymphoid cells forming germinal centre appearance are also visible. Areas with thinning destructive alveolar septa appeared. These findings indicated NSIP. In accordance to studies, if no definitive diagnosis could be established from physical examination and testings, then a diagnosis based on anatomic pathology examination with sample taken from surgical lung biopsy (in this case was done with VAS biopsy rather than Open lung biopsy (OLB) based on literatures claiming lower morbidity and mortality in VATS biopsy) is needed. ${ }^{8}$

The patient was thus given corticosteroid: prednisone $4 \times 5 \mathrm{mg}$, tapered off weekly for 4 weeks, i.e. $4 \times 5 \mathrm{mg}$ on first week, $3 \times 5 \mathrm{mg}$ on second week, $2 \times 5 \mathrm{mg}$ on third week, and $1 \mathrm{x} 5 \mathrm{mg}$ on $4^{\text {th }}$ week. This approach is i accordance to literatures, in which therapy on NSIP usually started with prednisone $0,5-$ $1 \mathrm{mg} / \mathrm{kg}$ IBW per day until a maximum dose of $60 \mathrm{mg} /$ day for a month, followed by 30 $40 \mathrm{mg} /$ day for 2 additional months. Therapeutic approach in this patient is following previous literature in which was said that therapy on NSIP usually started with prednisone $0,5-1 \mathrm{mg} / \mathrm{kg}$ IBW per day until a maximum dose of $60 \mathrm{mg} /$ day for a month, followed by 30 - $40 \mathrm{mg} /$ day for 2 additional months. If patient responds to therapy, or in patient with stable condition after therapy, the dose of prednisone was tapered off. Optimal drug admission duration is not yet known, but recommended gradual dose reduction is until 5-10 mg a day, or on the next day. ${ }^{2,3,9}$ According to literatures, years to months to follow, CTD could be found in patient with idiopathic NSIP, which is why periodic monitoring is needed. In this case, the patient was stable, however the possibility that CTD will manifest should be considered, ergo the 
patient was periodically monitored. In this case, the patient was stable, however the possibility that CTD will manifest should be considered. According to several studies, periodical monitoring of patients with NSIP should be done every 3-6 months., ${ }^{2,10}$

5-years-survival rate of patients with NSIP is around 91\% -92\%, and 10yearssurvival rate is $26 \%-40 \%$ in patients with NSIP showing components of fibrosis. Prognosis could vary depending on level of lung permanent damage, wherein fibrotic type NSIP has poorer prognosis than cellular type NSIP (which 5-years and 10-years survival rate is almost 100\%). Many patients with NSIP responded greatly to

corticosteroid. In this case, patient was in stable condition, and had been for 2 years with periodical follow up. The patient is expected to stay in stable condition. ${ }^{1,11}$

\section{Summary}

A 54-years -old male smoker, complaining cough and shortness of breath since the past 2 years, arising mostly after activities. Based on the complaints and confirmed with physical examination, laboratory, blood, sputum, and bronchoalveolar fluid flush examination,, and radiological examination combined by anatomical pathology examination, a diagnosis of Idiopathic fibrotic type NSIP is established.

Non specific interstitial pneumonia (NSIP) is a form of interstitial lung disease. On histology, it shows a temporally uniform interstitial process with varying proportions of interstitial inflammation and fibrosis.

NSIP is ethiologically defined as "idiopathic" or "secondary". Ergo diagnosis of NSIP is established with multidisciplinary team, i.e. Pulmonology department as clinician, Radiology department, and establishing the diagnosis by anatomic pathology department.

NSIP treatment relies on the cause, severity, and development. Therapeutic approach using corticosteroid by and large is greatly responded, using prednisone dose started from 0,5 - $1 \mathrm{mg} / \mathrm{kg}$ ideal body weight per day until maximum dose of $60 \mathrm{mg} /$ day for a month followed by $30-40 \mathrm{mg} /$ day for additional 2 months. The patient in this case was given prednison $4 \times 5 \mathrm{mg}$, tapered off 
weekly for 4 weeks, and showed great improvement as he was on stable condition.

According to literatures, years to months to follow, CTD could be found in patient with idiopathic NSIP, which is why periodic monitoring is needed. In this case, the patient was stable, however the possibility that CTD will manifest should be considered, ergo the patient was periodically monitored. In this case, the patient was stable, however the possibility that CTD is there, thus periodical monitoring is highly recommended. Prognosis could vary depending on level of lung permanent damage, wherein fibrotic type NSIP has poorer prognosis ( 5 and 10 years survival rate are $91 \%-92 \%$, and $26 \%-40 \%$ respectively) than cellular type NSIP (which

5-years and 10-years survival rate is almost $100 \%)$. Many patients with NSIP responded greatly to corticosteroid. In this case, patient was in stable condition, and had been for 2 years with periodical follow up. The patient is expected to stay in stable condition.

\section{References}

1. Collard HR, King Jr TE. Approach to the Diagnosis of Diffuse Parenchymal Lung Disease. InInterstitial Pulmonary and Bronchiolar Disorders 2016 Apr 19 (pp. 35-46). CRC Press.
2. Jennifer B.M. Pathology of Nonspecific Interstitial Pneumonia [Internet]. Medscape. 2016 [cited 10 November 2017]. Available from: https://emedicine.medscape.com/articl e/2078612-overview.

3. Flaherty KR. Causes, clinical manifestations, evaluation, and diagnosis of nonspecific interstitial pneumonia.

4. Antin-Ozerkis D, Rubinowitz A. An update on nonspecific interstitial pneumonia. Clinical Pulmonary Medicine. 2010 May 1;17(3):122-8.

5. Shifren A, editor. The Washington Manual Pulmonary Medicine

Subspecialty Consult.

Lippincott Williams \& Wilkins; 2006.

6. Johkoh T. Nonspecific interstitial pneumonia and usual interstitial pneumonia: Is differentiation possible by high-resolution computed tomography?. InSeminars in Ultrasound, CT and MRI 2014 Feb 1 (Vol. 35, No. 1, pp. 24-28). WB Saunders.

7. Romagnoli M, Nannini C, Piciucchi S, Girelli F, Gurioli C, Casoni G, Ravaglia C, Tomassetti S, Gurioli C, Gavelli G, Carloni A. Idiopathic nonspecific interstitial pneumonia: an interstitial lung disease associated with autoimmune disorders?. European Respiratory Journal. 2011 Aug 1;38(2):384-91.

8. Fruchter O, Fridel L, El Raouf BA, Abdel-Rahman N, Rosengarten D, Kramer MR. Histological diagnosis of interstitial lung diseases by cryotransbronchial biopsy. Respirology. 2014 Jul;19(5):683-8.

9. Wallis A, Spinks K. The diagnosis and management of interstitial lung diseases. Bmj. 2015 May 7;350:h2072. 
10. Kinder BW, Collard HR, Koth L, Daikh DI, Wolters PJ, Elicker B, Jones $\mathrm{KD}$, King Jr TE. Idiopathic nonspecific interstitial pneumonia: lung manifestation of undifferentiated connective tissue disease?. American journal of respiratory and critical care medicine. 2007 Oct 1;176(7):691-7.

11. Nunes H, Schubel K, Piver D, Magois E, Feuillet S, Uzunhan Y, Carton Z, Tazi A, Levy P, Brillet PY, Nicholson AG. Nonspecific interstitial pneumonia: survival is influenced by the underlying cause. European Respiratory Journal. 2015 Mar 1;45(3):746-55. 